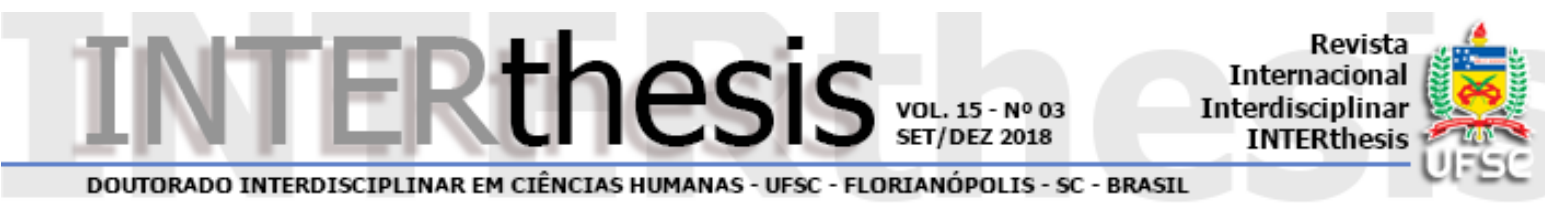

\title{
A CONSTRUÇÃO DISCURSIVA DO CORPO FEMININO NA MÍDIA ESPORTIVA: AS OLIMPÍADAS 2016
}

\author{
Tiago Pellim ${ }^{1}$ \\ Irlla Karla dos Santos Diniz ${ }^{2}$ \\ Gabriele Soares Ivanha ${ }^{3}$
}

\section{Resumo:}

O objetivo do estudo foi analisar a maneira como o corpo feminino é construído através da linguagem em duas reportagens publicadas por um grande portal de notícias esportivas durante as Olimpíadas Rio-2016. A análise se embasou nas discussões teóricas sobre a construção social e histórica do corpo feminino, bem como a relação entre gênero e esporte, considerando os aspectos textuais, discursivos e multimodais das notícias. Frente ao objetivo inicial da pesquisa, é importante refletir sobre como a indústria midiática constrói o corpo feminino em um megaevento esportivo como as Olimpíadas, considerando todo o histórico desigual entre os espaços ocupados por homens e mulheres no esporte. Como principais resultados, pode-se destacar que ainda enfrentamos desafios no que tangencia a imagem das mulheres e do corpo feminino na mídia esportiva, uma vez que há uma visão reducionista que privilegia o corpo estético e a família (aspectos tradicionalmente associados ao feminino), ao mesmo tempo em que sinaliza avanços ao colocar o esporte em primeiro plano em alguns momentos, mesmo que em uma visão exacerbada do mito/herói.

Palavras-chave: Gênero. Esporte. Mídia. Olimpíadas 2016. Análise do Discurso.

\section{INTRODUÇÃO}

No mundo atual em que mudanças de ordem social e política passam a alimentar um sentimento de deslocamento, impactando na forma como os indivíduos se percebem no mundo e como constroem suas identidades sociais, faz-se necessário reconhecer, segundo Fabrício (2004), a relevância que as práticas discursivas assumem nesse panorama de grandes transformações. Segundo a autora, a linguagem tem sido utilizada de modo cada vez mais estratégico em diversos campos da vida social, como a política, o trabalho e a mídia. Daí a importância dos estudos

\footnotetext{
1 Doutorando em Linguística Aplicada pela Universidade Estadual de Campinas. Professor do Instituto Federal de Educação, Ciência e Tecnologia de São Paulo, Capivari, SP E-mail: tiagopellim@ifsp.edu.br

${ }^{2}$ Doutora pelo Programa Interdisciplinar de Desenvolvimento Humano e Tecnologias. Professora do Instituto Federal de Educação, Ciência e Tecnologia de São Paulo, Capivari, SP E-mail: irllakarla@yahoo.com.br

3 Técnica em Química pelo Instituto Federal de Educação, Ciência e Tecnologia de São Paulo, Capivari, SP E-mail: soaresgabriele9@gmail.com
} 
que reconheçam a força da mídia na constituição de repertórios simbólicos que contribuem para a construção das identidades sociais.

A onipresença da mídia e sua cobertura ininterrupta do mundo geram, segundo Thompson (2004), um sentimento de "espetacularização da vida social", na qual tudo pode ser noticiado. Neste trabalho, tomemos como exemplo o fenômeno do esporte, que hoje se trata de uma linguagem universal espetacularizada por meio dos grandes eventos e dos interesses políticos e econômicos que atuam como pano de fundo em sua construção social.

Os Jogos Olímpicos, em especial, extrapolam a dimensão esportiva para se tornarem verdadeiras arenas de marketing e acordos econômicos mediados pelo discurso esportivo. Sob a égide dessa discussão, as mídias assumem um posto de destaque na disseminação das informações, venda de produtos, divulgação dos resultados, exploração de escândalos e demais situações que ocorram ao longo dos jogos, atuando diretamente na formação de opiniões.

Nesse âmbito, o presente artigo buscou refletir sobre como as práticas discursivas da indústria midiática esportiva constroem o gênero e o corpo feminino ao realizar a cobertura dos Jogos Olímpicos tendo em vista a analogia histórica entre masculinidade e o mundo dos esportes.

Em trabalho publicado em 2012, Mühlen e Goellner apresentam os resultados de uma pesquisa desenvolvida em 2008 durante a realização dos Jogos de Pequim, que buscou identificar as representações sobre a masculinidade e a feminilidade na cobertura dos jogos feita pelo portal de notícias Terra. Na ocasião, as autoras identificaram 2 categorias principais que serviam como pano de fundo para a construção do gênero dos atletas, a saber: os superatletas, que eram construídos a partir de suas vitórias, delineando, assim, a imagem do atleta como aquele que supera obstáculos e alcança a vitória pela superação; e as musas e musos, que tinham na ênfase de sua beleza a associação entre prática esportiva e saúde.

Passados oito anos desde aquele evento, este trabalho pretende retomar esse debate, com especial atenção para a maneira como o corpo feminino é discursivamente construído nas peças jornalísticas referentes aos Jogos Rio 2016. Para tanto, o objetivo do presente artigo é analisar duas reportagens publicadas por um grande portal de notícias esportivas que tinham como destaque atletas mulheres. A análise terá como foco as discussões teóricas sobre a construção social e histórica do corpo feminino, bem como a relação entre gênero e esporte. 


\section{GÊNERO E ESPORTE}

O esporte é um fenômeno social que está em constante movimento, isto é, vive processos de transformação em consonância com as demais instituições da sociedade, sendo influenciado pelos valores do meio social em que está inserido e atuando, também, como um disseminador desses fatores. Torna-se, portanto, impossível refletir sobre a cultura esportiva desconsiderando todas as tramas sociais elucidadas no campo político, econômico, da saúde e do lazer, que, de diversas maneiras, acabam interferindo na forma como o esporte é compreendido, vivenciado e consumido.

Nesse escopo, as questões de gênero também se constituem em marcadores sociais relevantes para o debate no campo esportivo. Para Devide (2005), o gênero se caracteriza como uma categoria em mutação, que se refere às práticas sociais relacionadas aos discursos, atitudes e comportamentos esperados para os sexos, seja masculino ou feminino. Isto é, são construções histórico-culturais que dizem respeito ao que a sociedade entende como típico da mulher ou do homem. Bortolini (2008), de maneira mais pontual, assevera que:

[...] falar de gênero não significa simplesmente falar "de mulher", mas de relações de poder, materiais e simbólicas, que envolvem todos os seres humanos. Significa visibilizar e problematizar os modos de significação dos corpos, dos jeitos de ser, de andar, de falar. (BORTOLINI, 2008, p. 32).

Ressalta-se, a partir da citação anterior, que o debate sobre gênero passa pela discussão de como os corpos biológicos são compreendidos no interior das relações de poder, relações estas que são perpassadas pelos discursos que constroem imagens do que é ser feminino ou masculino. Tais discursos são produzidos nas diversas esferas institucionais que compõem a sociedade, tais como a ciência, a medicina, a escola, a religião e, o que será foco deste estudo, a mídia.

No campo esportivo, o conceito de gênero nos auxilia a analisar mais detalhadamente o que está por trás de práticas tão corriqueiras como a exploração do corpo da mulher nos jogos, as dificuldades de encontrar técnicas e árbitras em competições de alto nível, os uniformes que sensualizam os corpos, os comentaristas e as notícias que focam nos atributos físicos ao invés do desempenho esportivo, dentre outras situações a que as atletas são expostas com frequência. Isso acontece porque o esporte, como fenômeno social que é, transpõe para o seu contexto comportamentos sociais que demarcam estereótipos de gênero e que precisam ser 
questionados. Como salientam Mühlen e Goellner (2012, p. 167), "o esporte, como qualquer outra prática cultural, é generificado e generificador. Ou seja, seu acontecer está perpassado pela (re)produção de masculinidades e feminilidades, e estes marcadores identitários não são neutros nem universais".

Historicamente, o esporte foi denotado como uma prática hegemonicamente masculina, que excluiu e/ou reservou espaços diferentes para serem ocupados pelas mulheres. Esse panorama evidenciou-se a partir da construção social que temos da mulher, que inclui a obrigação da maternidade, da sensibilidade e o dever de se dedicar ao lar. Logo, algo que exige força física, treinamentos intensos e vigorosos, como o esporte, tradicionalmente não foi considerado como uma prática adequada ao corpo feminino (DEVIDE, 1995).

Para entender melhor a relação entre gênero e esporte, nos aprofundaremos, a seguir, nos processos sociais que constroem o corpo feminino de formas bastante particulares.

\section{A CONSTRUÇÃO DO CORPO FEMININO}

Falar das construções do feminino em nossa cultura implica, necessariamente, em problematizar a associação entre mulher e beleza. O modelo identitário calcado na tríade beleza-juventude-saúde impõe, segundo Novaes (2010), a estética como nova forma de controle sobre o corpo feminino. Percebe-se aqui o privilégio que o corpo assume na construção da subjetividade feminina. Ainda de acordo com Novaes (2010, p. 35), "a mulher tornou-se condenada a ser um corpo, ou ainda, a ser reduzida a sua anatomia", de forma que se torna imperativo refletir acerca do "lugar que o corpo assume como valor social e a consequente regulação que o acompanha" (grifos originais).

Seguindo um pensamento foucaultiano, Novaes (2010) destaca que o corpo se tornou objeto de uma forma de controle bastante específica. Uma forma de regulação que exerce seu poder através da hiperestimulação ao invés da repressão. Conforme sugere Foucault (1979, p. 147), "encontramos um novo investimento que não tem mais a forma de controle-repressão, mas de controle-estimulação: 'Fique nu... mas seja magro, bonito, bronzeado!"”.

Aqui não se pode deixar de considerar o papel da mídia na operação e manutenção desse "controle-estimulação". Em se tratando do corpo feminino, em específico, Del Priore (2009, p. 15) afirma que "mais do que nunca a mulher sofre 
prescrições. Agora não mais do marido, do padre ou do médico, mas do discurso jornalístico e publicitário".

Andrade (2003, p. 108) propõe pensar a mídia como uma instância pedagógica que atua no meio social "ensinando aos corpos masculinos e femininos, adultos e infantis, modos de se comportar e de se relacionar com as coisas do mundo". A mídia seria uma dessas instâncias pedagógicas na medida em que "os ensinamentos produzidos e reproduzidos pelas instâncias midiáticas conformam determinados tipos de corpos como 'ideais'" (op.cit., p. 119), privilegiando certos repertórios de conduta e gerando parâmetros de normalidade calcados no binômio normal versus desviante (FABRÍCIO, 2004).

A partir do que já foi aqui discutido, é possível começar a pensar no corpo para além do seu dado biológico para compreendê-lo como resultado de uma complexa construção histórica e cultural que se dá através do discurso. A linguagem, ao invés de apenas refletir ou descrever um corpo material que já preexiste ao discurso, constrói o próprio corpo, isto é, a existência e a materialidade do corpo se dão através do discurso. Como explica Goellner (2003, p. 29), "a linguagem não apenas reflete o que existe. Ela própria cria o existente e, com relação ao corpo, a linguagem tem o poder de nomeá-lo, classificá-lo, definir-lhe normalidades e anormalidades".

Importante destacar que não se trata de negar o fator biológico em sua constituição, mas de reconhecer que os sentidos atribuídos a cada corpo são socialmente e culturalmente construídos por meio do discurso, portanto não naturais e passíveis de serem questionados.

Nesse sentido, o presente trabalho busca colocar sob análise os repertórios simbólicos acionados pela mídia esportiva sobre o corpo feminino, problematizando tais repertórios e as identidades e ideais corpóreos constituídos a partir daí.

\section{ENQUADRE METODOLÓGICO}

Buscando responder à questão inicial da pesquisa (como as práticas discursivas de um grande portal da mídia esportiva constroem o gênero e o corpo feminino ao realizar a cobertura dos Jogos Olímpicos Rio 2016), foram coletadas todas as notícias que faziam referência a competidoras femininas publicadas no mês de agosto de 2016 (mês de realização dos Jogos) no portal de notícias Globo Esporte. A escolha por esse canal midiático se deu por ser este o maior site de notícias esportivas do Brasil. Além disso, o portal criou, no referido mês, uma página online 
específica para a divulgação de notícias relacionadas às Olimpíadas, o que atesta a importância dada ao evento na cobertura do site.

Ao final do processo de coleta dos dados, as reportagens foram categorizadas e interpretadas segundo seu principal conteúdo temático. Essa primeira análise permitiu que fossem selecionadas as reportagens de maior representatividade para os fins da pesquisa que foram analisadas segundo o modelo tridimensional de análise do discurso proposto por Fairclough (2001), complementado por uma análise multimodal do discurso. Para este autor, o exercício da análise do discurso deve incorporar três dimensões, a saber: o texto, cuja análise linguística se volta para o vocabulário, estruturas gramaticais, coesão e estrutura textual; a prática discursiva, que foca nos processos de produção, distribuição e consumo do texto; e a prática social que procura interpretar os elementos textuais e discursivos mencionados anteriormente sob a ótica dos sentidos culturais, políticos e ideológicos que constituem o corpo social.

A seguir, são apresentadas e discutidas as análises de duas dessas reportagens que ilustram os sentidos mais recorrentes observados ao longo da pesquisa.

\section{ANÁLISE DOS DADOS}

\section{Reportagem 1: Recordista, Érika revela histórias por $\mathbf{3 3}$ tatuagens e mira pódio em seu quintal \\ (http://globoesporte.globo.com/olimpiadas/basquete/noticia/2016/08/recordista-erika- revela-historias-por-33-tatuagens-e-mira-podio-em-seu-quintal.html)}

A reportagem foi publicada no dia 05/08/2016, portanto antes das competições terem início. A manchete revela três informações sobre a atleta Érika: ela é recordista, tem 33 tatuagens e está em busca de uma medalha olímpica. Note-se que pelo título não é possível saber o esporte praticado pela atleta.

Embora seja adjetivada como "recordista", não se sabe, apenas pelo título, que recorde Érika detém. Tal informação só fica clara quando lemos o lead, ou seja, o primeiro parágrafo da reportagem que destaca suas principais informações:

Do alto de seus $1,97 \mathrm{~m}$, Érika de Souza não chama apenas a atenção pela postura forte, o olhar determinado e o talento nas quadras. Aos 34 anos, a pivô também tem 
o estilo como marca, e uma história de vida ilustrada em 33 tatuagens. Com desenhos relacionados à família, ao esporte e à fé, ela é a recordista entre os 465 atletas brasileiros na Rio 2016.

Logo no início, Érika é destacada por seu porte físico, determinação e talento, características estas relacionadas à sua atuação como atleta. Já o recorde mencionado na manchete e que, a princípio, pode ter sido associado a sua carreira esportiva, na verdade diz respeito ao número de tatuagens que ela possui, o que sugere que questões relativas à estética do corpo da atleta se sobrepõem às informações sobre sua possível preparação para os jogos.

A reportagem segue destacando seu desempenho nas últimas Olimpíadas, bem como as tatuagens feitas em memória de cada uma dessas participações. Para ilustrar essas informações, a primeira imagem apresentada retrata uma parte da perna da jogadora, com ênfase exclusiva para as tatuagens (figura 1), sendo que até este ponto ainda não conhecemos a fisionomia da atleta. A legenda que acompanha a foto reforça, mais uma vez, a informação de que é a jogadora brasileira com maior número de tatuagens: "Com 33 tatuagens, Érika de Souza é a recordista entre brasileiros na Rio 2016".

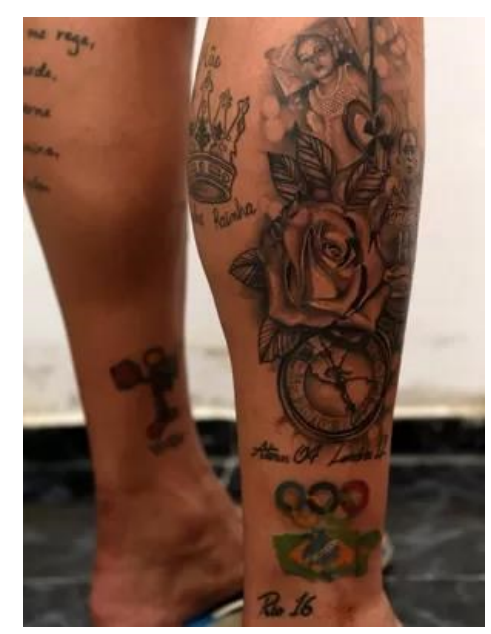

Figura 1 - Com 33 tatuagens, Érika de Souza é a recordista entre brasileiros na Rio 2016 Fonte: Globo Esporte

O texto da reportagem segue explicando o motivo de algumas das tatuagens mais significativas feitas por Érika, sendo a maioria delas relacionada a sua profissão e a sua família.

A seguir, temos mais uma imagem. Dessa vez, Érika foi fotografada em movimento, no momento em que se prepara para fazer um arremesso (figura 2). Cabe 
destacar que essa é a única foto que retrata a atleta jogando. Ainda assim, percebemos que o foco da imagem não é ressaltar seu desempenho esportivo, e sim, mais uma vez, seu corpo coberto por tatuagens.

A essa altura já é possível perceber como a atuação profissional da atleta é utilizada como pano de fundo para, na verdade, construir-se uma imagem estética do corpo de Érika. Esse entendimento ganha força quando se analisa a legenda que acompanha a figura 2: "Além do corpo coberto por tatuagens, Érika, vaidosa, gosta de ter sempre unhas com esmaltes coloridos e desenhos pintados à mão. Em todo lugar que vai, a primeira coisa que procura é uma manicure". Chama atenção a desconexão entre o conteúdo da imagem e da legenda. Enquanto a imagem remete ao seu desempenho como jogadora de basquete, a legenda explora sua estética, construindo a atleta como uma mulher vaidosa que gosta de pintar as unhas.

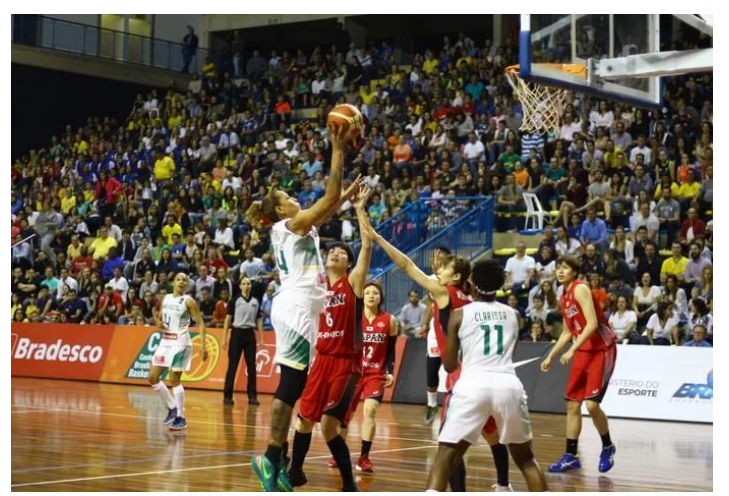

Figura 2 - Além do corpo coberto por tatuagens, Érika, vaidosa, gosta de ter sempre unhas com esmaltes coloridos e desenhos pintados à mão. Em todo lugar que vai, a primeira coisa que procura é uma manicure

Fonte: Globo Esporte

Nesse momento faz sentido retomarmos o apontamento feito por Novaes (2010) sobre como a estética acaba por se tornar uma nova forma de controle sobre o corpo feminino. Ter que procurar uma manicure em todo lugar a que se vai é um exemplo do "controle estimulação" mencionado por Foucault (1979) que reforça a correlação entre feminilidade e beleza. Tal reflexão evidencia como a mídia reforça signos sociais atrelados à compreensão hegemônica que temos da feminilidade.

Além da sobreposição do "corpo estético" em relação ao "corpo atlético", a reportagem se destaca por construir Érika como uma pessoa ligada às suas raízes familiares, como se observa no seguinte trecho:

- A minha avó, depois que eu perdi a minha mãe, é a minha musa inspiradora, a pessoa que eu mais respeito, mais tenho admiração, a minha avó sofreu bastante 
depois que perdeu a minha mãe, era ela e a minha mãe o tempo todo, então ela é minha avó-mãe. Ela me ajudou muito (...) revelou a atleta, campeã da WNBA pelo Los Angeles Sparks, em 2002, jogando ao lado de um de seus maiores ídolos, a americana Lisa Leslie, em sua primeira de 11 temporadas nos Estados Unidos.

Esta passagem é ilustrativa de como o texto privilegia as informações e depoimentos de cunho pessoal em relação às informações relacionadas a sua vida profissional, como o fato de já ter jogado 11 temporadas nos Estados Unidos e de já ter sido campeã da WNBA, a maior liga de basquete do mundo, dados que ganham pouco destaque ao final do parágrafo.

O texto é, mais uma vez, acompanhado de uma imagem (figura 3). Percebe-se que a atleta está fazendo um treinamento físico, embora o foco não seja sua atuação e sim suas tatuagens. Essa leitura é referendada pela legenda da foto: "Mesmo com as meias e o uniforme da seleção, é possível perceber as tatuagens de Érika". O uso da conjunção "mesmo" dá a atender que o número de tatuagens da jogadora é tão grande que nem seu uniforme consegue ofuscá-las, reforçando, assim, seu título de "recordista".

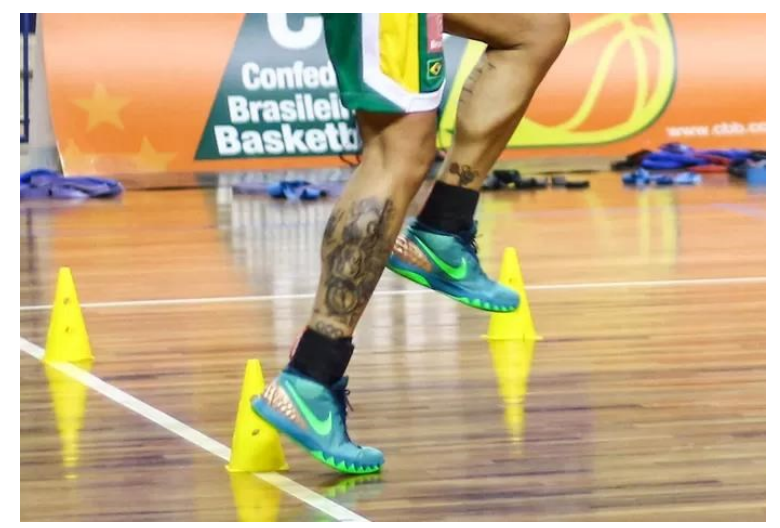

Figura 3 - Mesmo com as meias e o uniforme da seleção, é possível perceber as tatuagens de Érika

Fonte: Globo Esporte

Outro exemplo em que se nota a ênfase desigual dada aos feitos esportivos de Érika quando comparados aos comentários sobre seu corpo tatuado pode ser encontrado no trecho a seguir. Os "sonhos" conquistados por Érika nas quadras (títulos na WNBA e em diferentes países) só são mencionados rapidamente ao final de um parágrafo que comenta a tatuagem de "caçadores de sonhos" da atleta. 
As palavras de fé, as estrelas, a bola de basquete com a frase "mi vida", as rosas e o amuleto indígena dos caçadores de sonhos [...] também têm um significado especial. Feito nos Estados Unidos, o filtro traduz a sua forma de ver o mundo, uma constante busca por sonhos. Muitos se realizaram. Títulos na WNBA, na Espanha, na Hungria e no Brasil.

Encerrando a matéria, segue-se uma sequência de 9 fotografias $^{4}$ da jogadora das quais seis focam partes específicas do corpo da atleta com o intuito de revelar detalhes de suas tatuagens. Há ainda uma foto de Érika bebê e uma foto sua com seus irmãos que servem para corroborar a imagem construída de alguém que possui laços estreitos com a família. Finalmente, há apenas uma foto em que a jogadora está sozinha, segurando uma bola de basquete e olhando para frente, sendo a única imagem que não focaliza explicitamente as tatuagens da jogadora.

As análises textual, multimodal e discursiva da reportagem nos permitem sugerir que, enquanto prática social, este texto constrói o corpo feminino da atleta como um "corpo estético" ou, ainda, um "corpo vitrine" que dispõe suas marcas (as 33 tatuagens). Pouca visibilidade é dada ao desempenho esportivo da atleta, algo que se esperaria de um portal de notícias esportivas. Buscando uma aproximação com a literatura, temos nessa reportagem um reforço dos estereótipos atribuídos ao corpo feminino, uma vez que, mesmo diante de uma competição olímpica no Brasil, um portal esportivo prioriza uma matéria sobre tatuagens, o cuidado com as unhas e a relação afetiva com a família. Em outras palavras, percebemos como a mídia exerce sua "função pedagógica" (ANDRADE, 2003) ao atualizar aquilo que se espera de um corpo feminino, notadamente o cuidado com a beleza.

\section{Reportagem 2: Larissa/Talita desbanca time dos EUA, faz Arena tremer e avança às oitavas \\ (http://globoesporte.globo.com/olimpiadas/volei-de-praia/noticia/2016/08/larissa-e- talita-dao-show-desbancam-americanas-e-fazem-arena-tremer.html)}

A reportagem foi publicada no dia 09/08/2016 e faz referência à vitória da dupla brasileira de vôlei de praia feminino sobre os EUA. No entanto, já no título da reportagem é possível notar, pela escolha lexical feita, que não se trata de uma vitória qualquer. $\mathrm{O}$ jogo parece ter sido eletrizante, e as jogadoras brasileiras muito

\footnotetext{
${ }^{4}$ Por motivo de espaço, as imagens não foram reproduzidas aqui, mas podem ser recuperadas na reportagem através do link disponibilizado no início dessa análise.
} 
superiores às suas adversárias, tanto que fizeram a "Arena tremer". Este entendimento é corroborado pelo subtítulo, que afirma: "Dupla brasileira confirma favoritismo sobre Fendrick/Sweat" e "faz a estrutura de Copacabana balançar".

A Arena do Vôlei de Praia literalmente tremeu com Larissa e Talita. A dupla brasileira confirmou o favoritismo e venceu com muita tranquilidade as americanas Lauren Fendrick e Brooke Sweat, pelo placar de 2 a 0, com parciais de 21/16 e 21/13. O resultado garante vaga para a equipe nas oitavas de final. O show do time brasileiro empolgou a torcida na Praia de Copacabana, que, por algumas vezes, fez a estrutura metálica balançar ao interagir com os chamados do animado locutor do jogo. A Arena tem a altura de um prédio de sete andares em seu ponto mais alto e capacidade para cerca de 11,5 mil pessoas.

O lead da matéria reforça as ideias apresentadas na manchete e no subtítulo. Expressões como "a Arena do Vôlei de Praia literalmente tremeu", "a dupla confirmou o favoritismo", "venceu com muita tranquilidade" e "show do time brasileiro" dão a ideia de que a dupla brasileira já era considerada, de antemão, superior à dupla adversária. No fim do parágrafo, ao comparar a Arena de competições a um prédio de sete andares com "capacidade para cerca de 11,5 mil pessoas", reforça-se a ideia de que o jogo ou "show" tenha sido muito empolgante, sendo capaz de "balançar" essa "estrutura metálica".

Em seguida, o texto traz uma fala da jogadora Larissa que, além de comentar o desempenho da dupla no jogo, ressalta a importância de se "jogar uma Olimpíada dentro de casa" com o apoio da torcida: "A torcida deu um show".

Nesse ponto da reportagem, tem-se a imagem de uma mulher vestindo uma camiseta na qual está estampada a foto da dupla de jogadoras brasileiras (figura 4). Mas não se trata de uma torcedora qualquer. A legenda revela que esta é a esposa de Larissa, uma das jogadoras brasileiras. Cabe destacar que Lili, como é chamada, não é mencionada em nenhum outro momento no corpo do texto. A inclusão de sua imagem nesse ponto da reportagem parece ser uma tentativa de ilustrar o depoimento dado por Larissa acerca dos benefícios em se jogar no próprio país contando com o apoio da torcida. 


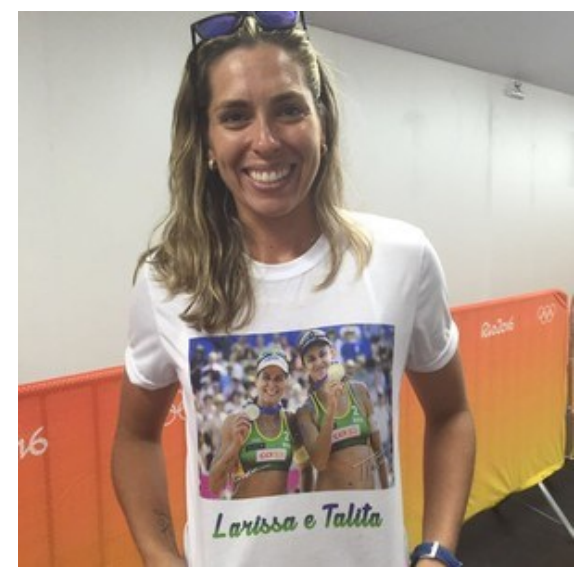

Figura 4 - Lili usa camisa em homenagem a esposa Larissa e a parceira Talita Fonte: Globo Esporte

A matéria passa, então, a abordar os detalhes do jogo, como se observa na seguinte passagem:

Os cinco bloqueios de Talita, especialista no fundamento, e a habilidade de Larissa, que encantou, marcaram a ótima atuação da dupla brasileira. Foram necessários 39 minutos para vencer. Trata-se da segunda vitória da equipe, na liderança do Grupo A, com quatro pontos. Na estreia, elas bateram as russas Ukolova e Birlova.

Mais uma vez, reforça-se a imagem positiva das jogadoras brasileiras, ao adjetivar Talita como "especialista em bloqueios" e Larissa como "habilidosa". A menção ao tempo total de jogo (39 minutos) sugere que a "ótima atuação" da dupla fez com que a vitória viesse com rapidez. Ficamos sabendo ainda que esta é, na verdade, a "segunda vitória da equipe". Antes, elas já haviam "batido" uma dupla de jogadoras russas. A escolha do verbo bateram em oposição a venceram ou mesmo derrotaram se configura como mais uma estratégia textual na construção positiva da imagem das jogadoras brasileiras.

A segunda imagem que acompanha a reportagem interrompe completamente o texto, tendo destaque no layout da matéria (figura 5). É acompanhada da seguinte legenda: "Larissa e Talita contra a dupla americana no Rio de Janeiro" e retrata a disparidade do duelo. Nela, Larissa e Talita ocupam posição central no primeiro plano. Parecem estar comemorando um ponto. Em contraposição, vemos a dupla americana em segundo plano, desfocadas. Quando observamos as expressões faciais das jogadoras que estão posicionadas de frente para a câmera, vemos Larissa apontando 
para sua companheira de equipe. Parece estar comemorando. Já a jogadora adversária tem um semblante sério e está calada. Nessa direção, esta imagem confirma o sentido construído até o momento de que a dupla brasileira foi superior à dupla estrangeira.

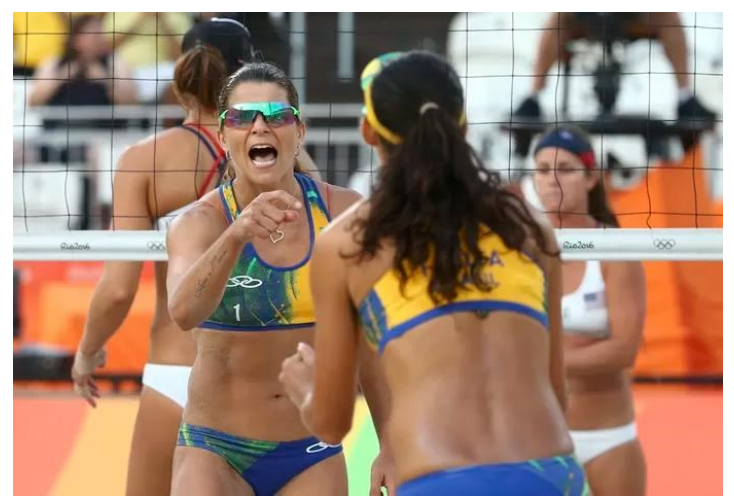

Figura 5 - Larissa e Talita contra a dupla americana no Rio de Janeiro Fonte: Globo Esporte

A partir daí, a matéria passa a abordar as habilidades individuais da dupla de jogadoras brasileiras. O texto enfatiza que "os bloqueios de Talita colocaram o Brasil à frente". Ao lado dessa informação, tem-se a imagem de Talita saltando em direção à bola (figura 6). A legenda é efusiva: "Talita voa na bola: brasileira fez cinco pontos de bloqueio". O emprego do verbo "voa" (ao invés de salta, por exemplo) parece conferir à atleta "superpoderes", de forma que poderíamos situá-la na categoria de "superatletas" mencionada por Mühlen e Goellner (2012).

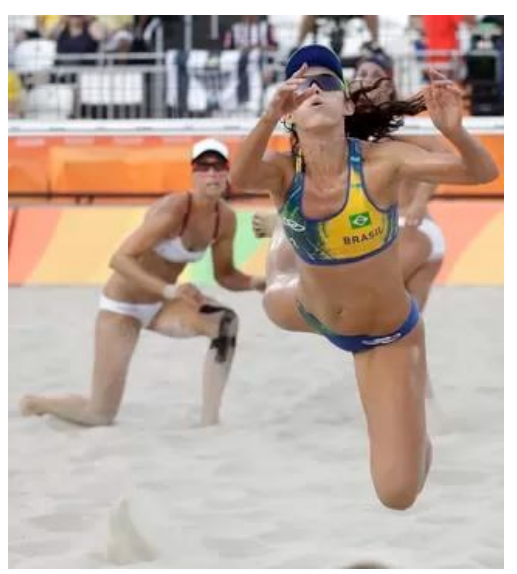

Figura 6 - Talita voa na bola: brasileira fez cinco pontos de bloqueio Fonte: Globo Esporte

$\mathrm{Na}$ imagem em si, note-se que Talita está retratada em pleno movimento, posicionada em primeiro plano, enquanto que a dupla americana encontra-se em segundo plano. O foco da fotografia é a ação, a "jogada", o "voo" da atleta, mais do que seu corpo ou estética. Como apontam Mühlen e Goellner (2012), as mídias têm 
grande interesse em estabelecer heróis olímpicos com o intuito de, entre outras coisas, vender os jogos e os seus produtos. A midiatização do esporte trabalha assiduamente em sua espetacularização, de forma que a linguagem, as imagens, as narrativas e as referências empregadas não são escolhidas por acaso, estão diretamente ligadas aos interesses socioeconômicos associados ao campo esportivo, o que nesse escopo, evidenciam o conceito de "superatletas".

Já em relação a Larissa, a jogadora é retratada como "habilidosa". O texto menciona que a dupla adversária não conseguiu "parar Larissa", o que sugere seu desempenho acima da média. O desempenho superior de Larissa fica ainda mais evidente quando se afirma que ela foi a única jogadora a marcar um ponto de saque no jogo (ace), contexto que reforça a categoria de "superatleta". Trata-se de agregar à performance valores positivos, exaltando sua determinação, habilidade ou até mesmo a força como atributos que a colocam em um patamar mais alto.

Finalizando a matéria, o texto apresenta o placar final da partida, além de retomar uma temática presente no título da reportagem: a festa da torcida na arena.

No fim, Larissa e Talita fecharam o jogo com larga vantagem: 21 a 13. A festa da torcida, que fez a estrutura da arena tremer, também teve a música "Vou festejar", de Beth Carvalho, cantada à capela.

Frente ao desempenho superior da dupla brasileira, a matéria enfatiza a diferença no placar final do jogo através da adjetivação "larga vantagem". O leitor é levado a concluir que a performance acima da média das jogadoras brasileiras que culminou com uma vitória expressiva foi o grande motivo de empolgação da torcida. Note-se o emprego da predicação "a festa da torcida", que remete o leitor ao campo semântico da comemoração, celebração, alegria, geralmente acompanhado de música. Essa leitura é reforçada pela indicação de que "também teve a música "Vou Festejar". Além disso, a menção de que tal canção tenha sido "cantada à capela", sugere, mais uma vez, a empolgação e animação dos torcedores.

A reportagem é encerrada com uma imagem que oferece uma dimensão visual da arena de competições, sendo que sua inclusão pode ser vista como uma estratégia de referenciação, indicando ao leitor a estrutura mencionada e descrita ao longo do texto. 
As análises textual, multimodal e discursiva da reportagem nos permitem sugerir que, enquanto prática social, este texto, diferentemente do anterior, constrói o corpo feminino das jogadoras como um "corpo atleta". Nenhuma das imagens enfoca o corpo sob uma ótica sexual, ainda que o uniforme do vôlei de praia revele muitos atributos físicos. Não se percebe a alusão a questões estéticas, como observamos na primeira matéria.

\section{CONSIDERAÇÕES FINAIS}

Inicialmente cabe destacar que as análises feitas aqui não pretendem ser exaustivas ou definitivas, sendo possível que outras leituras desses mesmos textos sejam feitas a partir de outros vieses teórico-metodológicos.

Na primeira matéria observamos que, como prática social, o texto privilegia os sentidos ligados à estética e à família, sentidos estes historicamente associados ao feminino. A análise multimodal revelou que o corpo da atleta foi esquadrinhado, focado nos mínimos detalhes, com um olhar que o objetifica. É notório que das 13 fotografias que acompanham a matéria, 8 sejam imagens de "recortes" do corpo da jogadora com o único intuito de revelar suas tatuagens. A única fotografia que retrata Érika em ação na quadra de basquete é acompanhada de uma legenda que enfatiza seus cuidados estéticos. Neste ponto faz sentido retomar a discussão feita no início do artigo e a afirmação de Novaes (2010, p. 35) de que "a mulher tornou-se condenada a ser um corpo". Neste caso, um "corpo recortado" ou um "corpo vitrine".

Se por um lado são raros os momentos em que a jogadora é enfocada a partir de seus atributos como atleta e as informações referentes a sua atuação esportiva ficaram em segundo plano, por outro lado ganharam força os sentidos que a construíam como uma mulher ligada à família e de alguém que se preocupa com a beleza. A afirmação de que Érika é vaidosa e está sempre em busca de manicures não pode ser vista apenas como descrição de um hábito. Tais discursos encontramse perpassados por julgamentos morais e significados sociais, como sugeriu Novaes (2010), que produzem ideais corpóreos (ANDRADE, 2003).

Já na segunda matéria analisada, observamos que comparecem com mais frequência os sentidos ligados à atuação esportiva/ profissional das atletas. As jogadoras são construídas como habilidosas, competentes e acima da média se comparadas às outras atletas, além de empolgarem a torcida. O texto desenvolve uma narrativa da partida que, para além de apenas descrever um fato ocorrido, atua na 
construção das identidades de Larissa e Talita como "superatletas", conforme Mühlen e Goellner (2012), com foco na espetacularização do esporte.

A análise multimodal revelou que, paralelamente aos itens linguísticos e textuais, as imagens ajudaram a construir um ideal de "corpo atlético", marcado pelos traços de força e habilidade. As imagens da dupla brasileira focaram as atletas em ação na quadra, fazendo jogadas e comemorando pontos marcados. O sentido de família comparece na imagem em que a esposa de Larissa é fotografada com a camiseta da dupla. Ainda assim, tal imagem parece ser representativa de toda a torcida brasileira. Dessa forma, embora nas duas reportagens seja possível recuperar o elemento familiar como sendo importante para as atletas, no primeiro texto essa dimensão foi muito mais enfatizada do que na segunda matéria.

Ao recuperarmos os resultados da pesquisa de Mühlen e Goellner (2012) sobre os Jogos de Pequim em 2008, é possível perceber como alguns sentidos permanecem nas matérias analisadas aqui. Poderíamos fazer uma correlação e sugerir que Érika, com o apelo estético por conta de suas tatuagens, teve seu corpo construído como uma vitrine, deixando o seu potencial esportivo em segundo plano, enquanto que Larissa e Talita se encontrariam na categoria dos "superatletas". Essa leitura nos faz refletir sobre a permanência de sentidos com os quais a mídia esportiva constrói suas narrativas sobre os atletas, reforçando ideais corpóreos e comportamentais.

Retomando Fairclough (2001), para quem o discurso contribui para a construção das identidades sociais, das relações entre sujeitos e dos sistemas de conhecimentos e crenças que informam a sociedade, podemos lançar a reflexão sobre como ou, até que ponto, a mídia esportiva questiona e/ou mantém ideais identitários relacionados ao gênero e ao corpo feminino. Nesse sentido, pesquisas que investigam os significados construídos pelos discursos midiáticos que nos constituem enquanto corpo social podem contribuir para questionar repertórios de sentido já cristalizados e, ao mesmo tempo, vislumbrar outras alternativas de vivência do gênero. 


\title{
THE DISCURSIVE MAKING OF THE FEMALE BODY IN SPORTS MEDIA: THE 2016 OLYMPICS
}

\begin{abstract}
:
This article aims to analyze the discursive making of female bodies in two pieces of news published in a big sports news website during the Rio 2016 Olympics. The analysis was based on theoretical discussions over the social and historical construction of the female body, as well as the relationship between gender and sports, considering the textual, discursive and multimodal aspects of the texts. Considering the initial objective of the research, it is important to reflect on how the media industry constructs the female body in a big sports event like the Olympics, bearing in mind the unequal history of spaces designed for men and women in sports. As main results, it is observed that there are still challenges to be faced concerning the way women and the female body are constructed in sports media, once it is common to find a reductionist perspective that associates women to family and aesthetics. At the same time, there is a progress as some pieces of news highlights the sport itself, even though bringing an exacerbated view of the myth/hero.
\end{abstract}

Keywords: Gender. Sports. Media. 2016 Olympics. Discourse Analysis.

\section{LA CONSTRUCCIÓN DISCURSIVA DEL CUERPO FEMENINO EN LOS MEDIOS DE COMUNICACIÓN DEPORTIVA: LOS JUEGOS OLÍMPICOS DE 2016}

\section{Resumen:}

El objetivo del estudio fue analizar la manera como el cuerpo femenino es construido por medio del lenguaje en dos reportajes publicados por un gran sitio de noticias deportivas durante la Olimpiada Rio-2016. El análisis se apoyó en las discusiones teóricas sobre la construcción social e histórica del cuerpo femenino, bien como las relaciones entre género y deporte, considerando los aspectos textuales, discursivos y multimodales de las noticias. Considerando el objetivo de investigación, es importante discutir sobre cómo la industria mediática construye el cuerpo femenino en un mega evento deportivo como son los Juegos Olímpicos, considerando todo el histórico desigual entre los espacios ocupados por hombres y mujeres en el deporte. Como principales resultados, es posible destacar que todavía enfrentamos desafíos en lo que se refiere a la imagen de las mujeres y del cuerpo femenino en los medios de comunicación deportiva, una vez que hay una visión reduccionista que privilegia el cuerpo estético y la familia (aspectos tradicionalmente asociados a lo femenino). Al mismo tiempo, se presentan señales de avances al poner el deporte como primer plano en algunos momentos, aunque en una visión exagerada del mito/héroe.

Palabras clave: Género. Deporte. Medios de Comunicación. Olimpíadas 2016.

Análisis del Discurso. 


\section{REFERÊNCIAS}

ANDRADE, S. Mídia impressa e educação de corpos femininos. In: LOURO, G.; FELIPE, J.; GOELLNER, S. (Org.). Corpo, gênero e sexualidade: um debate contemporâneo na educação. Petrópolis: Vozes, 2003. p.128-123.

BORTOLINI, A. Diversidade sexual e de gênero na escola: uma perspectiva interrelacional e intercultural. In: Bortolini, A. (Org.). Diversidade Sexual e de Gênero na Escola: educação, cultura, violência e ética. Rio de Janeiro: Pró-reitoria de Extensão, UFRJ, 2008. p.26-51.

DEL PRIORE, M. Corpo a corpo com a mulher: pequena história das transformações do corpo feminino no Brasil. São Paulo: Senac, 2009.

DEVIDE, F. Gênero e mulheres no esporte: história das mulheres nos Jogos Olímpicos Modernos. ljuí: Editora Unijuí, 2005.

FABRÍCIO, B. Mulheres emocionalmente descontroladas: identidades generificadas na mídia contemporânea. D.E.L.T.A., São Paulo, v. 20, n. 2, p. 235-263, 2004.

FAIRCLOUGH, N. Discurso e mudança social. Brasília: Editora UnB, 2001.

FOUCAULT, M. Poder-corpo. In: FOUCAULT, M. Microfísica do poder. Rio de Janeiro: Graal, 1979. p. 145-152.

GOELLNER, S. A produção cultural do corpo. In: LOURO, G.; FELIPE, J.; GOELLNER, S. (Org.). Corpo, gênero e sexualidade: um debate contemporâneo na educação. Petrópolis: Vozes, 2003. p.28-40.

MÜHLEN, J.; GOELLNER, S. Jogos de gênero em Pequim 2008: representações de feminilidade e masculinidades (re)produzidas pelo site Terra. Rev. Bras. Ciênc. Esporte, Florianópolis, v. 34, n. 1, p. 165-184, jan./mar. 2012.

NOVAES, J. Com que corpo eu vou?: sociabilidade e usos do corpo nas mulheres das camadas altas e populares. Rio de Janeiro: Editora PUC-Rio e Editora Pallas, 2010.

THOMPSON, J. A mídia e a modernidade: uma teoria social da mídia. Petrópolis: Vozes, 2004. 